Stoa

Vol. 11, no. 21, 2020, pp. 82-97

ISSN 2007-1868

\title{
LA PROPUESTA DE MAX SCHELER COMO RESOLUCIÓN ANTE EL PROBLEMA DE LA ININTELIGIBILIDAD DEL DOLOR
}

The Max Scheler proposal as a resolution to the problem of pain ininteligibility

\author{
MARISOL RAMÍREZ PATIÑO \\ Universidad Veracruzana \\ cirano.filosofia@gmail.com
}

RESUMEN: El siguiente escrito tiene por objetivo el esbozar algunas reflexiones desde el terreno de la filosofía y para ser más exactos, desde el ámbito de la fenomenología, en torno al problema del dolor. Particularmente, nos centraremos en la propuesta de Max Scheler, gran exponente de dicha corriente para quien las experiencias aflictivas (las cuales se hallan instauradas en la esfera afectiva y poseen el corazón como su centro) no han de ser entendidos nada más como meras sensaciones o estados cuyos contenidos se muestran al ser humano como vacíos, subjetivos e incomunicables por el simple hecho de erigirse dentro del terreno sentimental. Al contrario, entrañan una dirección y un sentido bien definido (encarnado bajo la idea del sufrimiento), mismo que escapa a la mirada y la comprensión del proceder del racionalismo clasico aunque no por ello ha de considerarse como algo ilógico- y cuyo alcance toca incluso el terreno de lo metafísico y lo esencial.

PALABRAS CLAVE: Dolor · Sufrimiento · Valores · Fenomenología · Max Scheler.

ABSTRACT: The following writing pretends to outline some reflections from the phenomenology's ground around the problem about pain. Particularly we will focus on the proposal of Max Scheler, great figure of that movement, for whom the afflictive experiences (which are settled in the affective sphere and possess the heart as their

Recibido 10 de Enero de 2020

Aceptado 20 de Enero de 2020 
center) should not be understanded just as mere sensations or states whiose their contents are shown to the human being as empty, subjective and incommunicable for the simple fact of being stand on the sentimental ground. On contrary, they keep a well defined direction and sense (encarnated under the ides of suffering), same that escapes to the gaze of the classic racionalism - although not for that should be considerded as ilogicall — and whose reach touches the ground of the metaphysical and the essential.

KEYWORDS: Pain · Suffering · Values · Phenomenology $\cdot$ Max Scheler.

\section{Introducción}

Dentro del terreno de los afectos advertimos que el dolor es sin duda una de las experiencias más bruscas y a su vez más complejas que el hombre tiene que atravesar. Tiene que hacerlo porque el dolor no es selectivo, se constituye como un hecho natural e ineludible no sólo para la vida humana, sino también para todos aquellos seres que sean susceptibles de detentar sensibilidad, pues, así como Aristóteles lo señaló: "allí donde hay sensación hay también dolor y placer" (De anima, II, 1, 413b pp. 20-25). No obstante, y pese a este carácter universal que el dolor posee, lo cierto es que todavía en nuestros días dicha vivencia constituye para el hombre un auténtico misterio. Lo anterior se debe (entre otros factores) a que no existe un único parámetro para evaluar el dolor, dificultando con ello la posibilidad de establecer una rotunda y exclusiva definición. Efectivamente, el dolor se vislumbra como una experiencia única, propia, inalienable, de carácter desagradable y difícil para el ser humano que, si bien posee una parte orgánica, el hecho de que también se instaure dentro de la esfera sentimental le vale ser presa de ciertas ambigüedades e incluso hasta no pocos prejuicios que han caracterizado dicho terreno, dificultando aún más su comprensión. Es más, se ha llegado a considerar al dolor como una vivencia impedida epistemológicamente hablando, de índole irracional e ininteligible. ${ }^{2}$ Consideramos que la desvalorización en que se puede llegar a incurrir con respecto a la problemática del dolor (al menos desde una perspectiva filosófica) posee como base una seria cadena de equívocos provocada

${ }^{2}$ Cabe mencionar aquí, por ejemplo, a la teoría de la identidad, surgida en la segunda mitad de los años cincuenta por U. T. Place, H. Feigl y J. J. C. Smart, principalmente, la cual afirmaba que las propiedades mentales son determinadas propiedades del cerebro, cuya identificación y estudio correspondían a la neurofisiología. Con base en lo anterior, una determinada propiedad mental (en este caso, sentir un dolor) se conectaría necesariamente con una determinada propiedad física (digamos, un estado de excitación de las fibras C), presuponiendo así una correspondencia biunívoca entre ambos elementos. Cfr. Moya, Carlos J., Filosofía de la mente, Publicaciones Universidad de Valencia, 2004, p. 89. Evidentemente, esta teoría no eludió a las críticas, siendo la objeción de Saul Kripke una de las de mayor alcance: “Según Kripke 'dolor' y 'excitación de las fibras C' son designadores rígidos. Nada distinto del dolor (de la experiencia, la sensación del dolor, nada que no se sintiera así) podría ser o haber sido dolor. Y nada distinto de la excitación de las fibras C podría ser o haber sido la excitación de las fibras C. Por lo tanto, 'el dolor es (idéntico a) la excitación de las fibras C', si es verdadero, es necesariamente verdadero. Pero parece claramente erróneo pensar que no pueda haber dolor sin excitación de las fibras C. El enunciado en cuestión, pues no es necesariamente verdadero. Pero entonces es falso, y con él la teoría según la cual los estados de conciencia son estados del cerebro" p. 92. 
por la falta de un enfoque adecuado que sea capaz de entablar un debido tratamiento en torno a su naturaleza. Hemos de buscar una postura que admita la compenetración entre las experiencias de índole afectiva y el análisis racional, a través de la cual pueda obtenerse un conocimiento integral del dolor sin caer en relativismos o anarquismos conceptuales: una reflexión en torno a la arquitectura de nuestro pensamiento emanada desde nuestro propio actuar, desde la complejidad de nuestra conciencia que sea capaz de abordar cada una de las dimensiones del ser humano (desde su sensibilidad corpórea hasta su espiritualidad) puesto que el dolor parece tener la peculiaridad de tocar de algún modo todos y cada uno de dichos flancos. Nos parece que dicha visión la encontramos en la fenomenología y para ser más exactos, en las reflexiones de corte ético-antropológico de Max Scheler, para quien las experiencias aflictivas no han de ser entendidas nada más como meras sensaciones o estados cuyos contenidos se muestran al ser humano como vacíos, subjetivos e incomunicables por el simple hecho de erigirse dentro del terreno sentimental. Al contrario, el dolor en general entraña, ciertamente, una dirección y un sentido bien definido mismo que escapa a la mirada metódica y racionalista - aunque no por ello ha de considerarse como algo ilógico- y cuyo alcance toca incluso el terreno de lo metafísico y lo esencial.

\section{Buscando el origen el problema: la ininteligibilidad del dolor}

¿Cómo hemos de definir al dolor? La pregunta en sí ya es problemática; si nos abocamos en su etimología, la palabra dolor proviene del latín dolor, doloris cuyo sufijo (-or) refiere a la acción de un efecto o resultado. Atendiendo lo dicho por la Real Academia Española (2001), el dolor se entiende como "aquella sensación molesta y aflictiva de una parte del cuerpo por causa exterior o interior" y también como "un sentimiento de pena y congoja".

Generalmente se distingue del placer (aunque no han de entenderse necesariamente como dos principios contrarios), ${ }^{3}$ el cual entenderemos desde un sentido tradicional y lato como un afecto agradable originado usualmente por la satisfacción de ciertas necesidades, ya sean provenientes de la sensibilidad física (placer sexual), de las facultades psíquicas (placer al imaginar, recordar, fantasear) o bien, puede proceder de

${ }^{3}$ La historia de la filosofía se ha encargado de ubicar al placer y al dolor como dos polos bien distintos entre sí que han de excluirse de una forma radical. Sin embargo, dicha postura ha tenido que flexibilizarse al admitir la existencia de una gran compenetración entre ambos principios, de suerte que nos es posible experimentar episodios dolorosos, pero que implican a su vez estados de placer. La experiencia cotidiana está repleto de muestras de este tipo, por ejemplo, tenemos a las prácticas sexuales sadomasoquistas, en donde la aplicación de dolor, ya sea físico o psicológico conlleva al mismo tiempo a un estado de placer. Cosa similar se observa en los actos de automutilación a través de la cual una persona se hace daño a sí misma (cortarse los brazos o piernas, arrancarse el cabello, pellizcarse o golpearse, etcétera) para obtener un estado de bienestar. Podría ser un ejemplo también algunas comidas cuyos ingredientes causan malestar y dolor en el sujeto pero que a su vez genera una sensación agradable, placentera en tanto su sabor (una comida picante). Sin embargo, no ha de inferirse de esto una identificación rotunda entre dolor y placer, pues representan dos elementos profundamente distintos desde su base más elemental. 
la contemplación (placer estético) o en la valoración (placer vinculado al bien), etcétera. Otra definición, que se utiliza habitualmente dada su amplitud dentro de los rubros de la medicina, la psicología e incluso la filosofía, es la formulada por el subcomité de taxonomía de la Asociación Internacional para el Estudio del Dolor (IAPS por sus siglas en ingles) que lo describe como "una experiencia sensorial desagradable asociada con una lesión hística real o potencial, o que se describe como ocasionada por dicha lesión o cuya presencia es revelada por manifestaciones visibles y/o audibles de conducta” (1994, pp. 209-14). Pero, ¿acaso todas estas definiciones se acercan a lo que realmente vivenciamos por dolor?

Pese a los intentos realizados por el ser humano desde la antigüedad para enmarcar al dolor en una definición absoluta y univoca, lo cierto es que todas han resultado insuficientes. "Es imposible definir al dolor, uno no puede describirlo, sólo es materia de experiencia. No se puede hablar del dolor con D mayúscula... es una sucesión de segundos, una sucesión de minutos; por eso resulta tan difícil de soportar" (Davis 1996, p. 15). Si bien existe una parte orgánica contenida en el dolor, es decir, hasta cierto punto éste podría entenderse simplemente como un mecanismo de transmisión neurológica o el resultado de un proceso bioquímico, la realidad es que el dolor no puede quedarse sólo en dicha esfera, puesto que también ha de comprenderse como una experiencia subjetiva, "quizás, un arquetipo de la subjetividad que sentimos sólo en la soledad de nuestra mente individual" (p. 15), en donde se integran una serie de aspectos capaces de modificar la misma vivencia dolorosa (ya sea en la sintomatología o su intensidad) y provocar con ello reacciones y sensaciones diferentes en cada individuo. ${ }^{4}$ Un ejemplo de lo anterior señalado sería la tolerancia que los individuos muestran hacia el dolor, es decir "la capacidad para proseguir con una actividad a pesar de la percepción del dolor" (Michael 2003, p. 764), y que varía ampliamente entre los hombres debido a que en ella influyen factores genéticos (el umbral de dolor que se posea), psicológicos (la conciencia, voluntad, percepción de esfuerzo) y socioculturales. Muestra de ello podría ser cualquier deportista cuya disciplina le permite alcanzar una mayor tolerancia al esfuerzo físico y sus efectos dolorosos, dicho sea, en comparación con otra persona que no estuviese acostumbrada a practicar ejercicio físico alguno. Se observa, entonces, que la experiencia dolorosa que genera una misma actividad se desarrolla con distinta magnitud en ambos sujetos.

Justo aquí es donde nos encontramos con uno de los problemas más importantes (si no es que el principal) en torno a este tema: el carácter inaprensible contenido en la vivencia del dolor. A propósito, cabe mencionar las reflexiones de Leonardo Polo

\footnotetext{
${ }^{4}$ Basta recordar a propósito la definición propuesta por Melzack y Casey (1968), quienes —desde una postura médica y psicológica - ubicaron al dolor como una experiencia perceptiva tridimensional, o sea, con una vertiente sensorial-discriminativa (en donde se transmite la estimulación nociva, así como su intensidad y características espacio-temporales); una vertiente motivacional-afectiva (la percepción desagradable y aversiva que genera ansiedad así como conductas de escape y/o huida) y una vertiente cognitivo-evaluativa (de la cual se derivan las creencias, los procesos de atención, los aspectos culturales, etcétera). Cfr. Morerira, J., Guías clínicas de cuidados paliativos, Arán, Madrid, 2007, p. 92
} 
(1926-2013), filósofo de origen español para quien la idea del dolor simplemente no cabe en el pensamiento humano. En 1996, p. 208 Polo afirma: "Tenemos dolor, lo sentimos, lo sufrimos o aguantamos; lo que no cabe es pensarlo". Ciertamente, Polo no niega la existencia del dolor, ni que éste posea un cierto tipo de contenido que nos permita al experimentarlo o tener una conciencia en torno a él, sin embargo, considera que el dolor en sí mismo carece de un contenido extramental, imposibilitando así su entendimiento, dicho sea esto en comparación con otro tipo de sensaciones que fungen en el hombre como la materia prima de las ideas y dentro de los cuales cabe, inclusive, alguna suerte de intuición intelectual. Poseemos un concepto del dolor según Polo- como lo tenemos de la nada, es decir, se halla fuera de nuestro alcance epistémico, sin la posibilidad de conocerlo:

Tenemos conciencia del dolor como de una acometida; por tanto, no poseemos el dolor en la conciencia: ahí, en el lugar del objeto, el dolor es indescifrable, no sabemos que significa. Una grieta del pensar es ocupada por lo que llamamos dolor. Por eso duele, se sufre (p. 208).

Así, el considerar el dolor como una especie de realidad sin esencia supone la imposibilidad de ser examinado filosóficamente, es más, ni siquiera poder plantearlo de un modo directo, "porque no sabemos siquiera que preguntar, a donde dirigir la atención. El dolor no ofrece base suficiente a la investigación” (p. 209). Ante tal panorama, el autor nos sugiere abandonar la pregunta directa sobre la esencia del dolor, para indagar — de un modo más bien indirecto - acerca del fundamento desde el cual éste aparezca explicado.

\section{El método fenomenológico como solución ante la ininteligibilidad del dolor}

Pero, ¿es en verdad el dolor una vivencia impedida epistémicamente? Nuestra postura al respecto es negativa. En efecto, Polo comete el error de tratar al dolor como una entidad y preguntar acerca de su esencia como si se tratara de un objeto del mundo físico, dado que, en realidad, el contenido de dicho fenómeno no se encuentra susceptible de un correlato real de definición. De ahí que, si siguiéramos por el camino que nos propone el filósofo español, correríamos el riesgo de reducir al dolor a una experiencia mística de la cual no pueda hablarse más que por analogía o metáfora.

Acercarnos hacia la realidad del dolor posee sus complicaciones pues, como acabamos de mentar, no sólo nos enfrentamos con una mera percepción nociceptiva, sino también con una experiencia subjetiva que integra un cúmulo de sensaciones, pensamientos y conductas: "el dolor en sí mismo es una experiencia compleja, lo que quiere decir que contiene numerosos componentes (perceptivos, afectivos, crediticios, culturales, de género, familiares, sociales, médicos, etcétera) que se hallan soldados entre sí en lo que parece una única vivencia" (García \& López 2009, p. 28). Este carácter multiforme que posee la experiencia del dolor ha traído como consecuencia la necesidad 
de realizar un análisis que sea capaz de descomponerla en cada uno de sus elementos para así estudiarlos por separado, lo cual ha derivado también en la implementación de diversos métodos para este fin. Sobre este punto, Choza (1977), reduce el análisis del dolor a tres grandes categorías: el análisis psicofisiológico del dolor experimental, la evaluación de la experiencia subjetiva del dolor (análisis fenomenológico) y el análisis ontológico. Sin embargo, al no existir un único parámetro para evaluar el dolor y, por ende, ante la imposibilidad de establecer una rotunda y exclusiva definición, se le ha llegado a considerar al dolor como una vivencia impedida epistemológicamente hablando, de índole irracional e ininteligible.

La Fenomenología ofrece, ante lo anterior, un escenario diferente. Para este movimiento, la vida afectiva no es en modo alguno ilógica y sin significado, puesto que detenta - aún en sus formas más simples - un contenido accesible al pensamiento, mismo que se encuentra respaldado en la propia experiencia de la conciencia. Así, al considerar a la afectividad humana como "un continuo vivencial de una complejidad extraordinaria" (Vicente Arregui \& Choza 1992, p. 237), se abre la posibilidad de examinar algunos de ellos en sí mismos, según su propia dinámica y su relación con otros. También permite su percepción jerárquica a partir de la matización que les es dada y por último dicho miramiento de la vida afectiva admite su acceso hacia el mundo de la acción práctica, lugar en donde se contienen y aparecen los valores. Para Husserl, éstos eran de una naturaleza fenoménica, objetiva e intencional y se encontraban fundados en el sentimiento ${ }^{5}$, por eso: "si intentamos eliminar todo sentimiento del corazón humano pierden sentido todos los conceptos éticos tales como medio y fin, bien y mal, virtud y deber y los demás conceptos con ellos vinculados" (Kogan 1996, p. 256).

Cabe decir que, a pesar de que Husserl no tenía como principal interés el forjar una lógica del sentimiento, lo cierto es que sí lo alentó, siendo sus propios alumnos y colaboradores (Dietrich von Hildebrand, Max Scheler, Edith Stein, Martin Heidegger) y posteriormente diversos simpatizantes y seguidores del método fenomenológico (J.-P. Sartre, Merleau-Ponty, Michel Henry, etcétera) quienes retomarían éste y otros ámbitos de realidad o como el propio Husserl nombraba como "ontologías regionales"6 u "ontologías materiales", mismas que sólo llegó a esbozar, pero que considero fundamentales para la constitución de una "región absoluta" capaz de fundamentarlas a todas (Husserl 1962, §1.1 76, p. 169). A Max Scheler, por cierto, se le atribuye el haber sido el primero en forjar una base para la interpretación ontológica de lo afectivo.

${ }^{5}$ Husserl, al hablar de Sentimiento, no se refiere a un "sentimiento empírico, como en la moral inglesa: ni de un esteticismo ético al modo de Shaftesbury; ni siquiera a una emotividad pre-rracional como la que ha difundido Scheler, sino de una Razón en el meollo mismo de sentir, en lo que Husserl, lo mismo que Kant, denomina Gemüt, ánimo, esto es, el alma despojada de su connotación sustancial o religiosa”. (Kogan 1996, p. 256). De ahí que se considere que una de las aportaciones más importantes de Husserl al campo de la ética haya sido, precisamente, la racionalidad del sentimiento. Más tarde veremos cómo dicho posicionamiento es rebatido por Max Scheler.

${ }^{6}$ En donde el término región refiere a un horizonte específico de datos o Gegebenheiten. 


\section{La propuesta de Max Scheler}

Max Scheler es considerado como uno de los pensadores más sobresalientes del primer tercio del siglo XX, al punto de haber sido nombrado por Heidegger (2009, p. 64), tras la noticia de su repentina muerte, como "la potencia más fuerte en la Alemania de hoy; no, en la Europa actual e incluso en la filosofía del presente en general". Situado en el terreno de la fenomenología, Scheler desarrolló considerables aportes a los campos de la sociología, la psicología, la filosofía de la religión, la ética, la estética y la antropología filosófica, siendo esta última — desde una visión moderna - fundada por él. También se le reconoce a Scheler el haber emprendido un giro dentro del mismo proceder de la fenomenología, pues así como Husserl habría dirigido su atención primordialmente hacia la teoría del conocimiento, la lógica, las matemáticas, como a la filosofía de la ciencia; Scheler — estimulado en gran medida por San Agustín y Pascal - decide aplicar los principios metodológicos de la fenomenología hacia la reivindicación del carácter científico y positivo de la ética filosófica a través del análisis fenomenológico de la experiencia afectiva, cuyo objeto especifico es el valor.

En efecto, para el fenomenólogo muniqués los valores no son meras construcciones artificiosas basadas en convencionalismos o pretensiones utilitaristas; tampoco deben entenderse como el objeto de la volición o el deseo, ni tampoco dependen absolutamente de un sistema racional para ser comprendidos y ejecutados, sino que estos son en sí mismos entidades absolutas y objetivas que encarnan verdaderas esencias y relaciones de esencias a los cuales se accede a través de la llamada percepción sentimental, cuya característica primordial es su intencionalidad, o sea, su referencia constitutiva en relación a un objeto percibido. En palabras de Beites (2010, p. 244): "los valores no son ideas de la inteligencia, sino correlatos de actos originarios de 'sentir' o, en una traducción más explicativa, de 'percibir sentimental' (Fühlen), pues no se trata de meros estados sentimentales ciegos, sino de una referencia intencional afectiva al ámbito del valor". Según lo anterior, los sentimientos poseerían un cierto valor cognitivo - en tanto que son intencionales — puesto que no sólo indican la situación de nuestra propia subjetividad (en tanto que la afectan), sino que también pueden llegar a informar acerca de un objeto concreto e incluso, valorar la realidad. Citando al propio Scheler (2010, pp. 49-50):

Una cierta clase de sentimientos, al menos, da en el vivir mismo algo así como un "sentido", un "significado", por medio del cual el sentimiento refleja ciertas diferencias de valor [objetivas] de un ser, de un obrar o de un destino que nos acontece, o incluso las anticipa y proyecta ya antes de que se presenten.

El vértigo, el cansancio, el temor, etcétera, serían ejemplos de cómo los sentimientos pueden tener un sentido entrañado en su vivencia misma puesto, que nos advierten - escapando muchas veces al lenguaje de la razón- de un posible daño vital antes de que se presente. Sin embargo, esto también se presenta en los sentimientos ubicados 
en los estratos superiores: el pudor, que denota la protección de lo público su valor interior reservado, o el arrepentimiento, que descarga nuestro pasado, purificándolo y rechazándolo para liberarnos hacia el nuevo bien (pp. 49-50).

Cabe decir que el pensamiento de Max Scheler posee también una connotación antropológica. A través de la examinación de la vida afectiva, así como el acceso al mundo de valores y su orden jerárquico, el ser humano descubre que es "un ser que se trasciende a sí mismo, porque tiene una tendencia inherente a lo divino. Es un intermedio cósmico, dotado de un cuerpo propio que mira intencionalmente a Dios" (Estermann 2001, p. 93). Scheler, entonces, planea rescatar esta intuición primordial de nuestro yo espiritual y explicitarlo a través de juicios fenomenológicos, surgiendo así el proyecto de una antropología filosófica. Su objetivo es - basándose en un fundamento científico que pueda aplicarse de una forma central y básica en la reflexión filosófica- el de descifrar la particularidad del ser personal espiritual al mismo tiempo que determina su puesto singular en el conjunto del mundo y de la vida. La antropología filosófica también es capaz de ofrecer una respuesta integral a las preguntas sobre el sentido de la existencia humana, dado que representa además un ejercicio de autocomprensión.

En el caso del dolor y la aflicción en general, el muniqués nos dice que estos han de ser entendidos — por su esencia de estados sensitivos - como un hecho irreductible, un modo de ser fundamentales de la condición humana, imposibles de modificar. Sin embargo, más allá de esta fatalidad ciega, hay que reconocer la existencia también de "una esfera de sentido y una esfera de libertad, de donde parten las grandes doctrinas de salvación" Scheler (2010, p. 51).

Efectivamente, para el fenomenólogo "todos los sufrimientos y dolores de las criaturas tienen un sentido, al menos un sentido objetivo (p. 52). Un primer acercamiento nos revelaría que todas las experiencias aflictivas, así como todas las vivencias placenteras expresan respectivamente una inhibición o un fomento de la vida (p. 52). Tal afirmación — rescatada del pensamiento aristotélico — resulta ser, al menos en principio, correcta. Basta señalar lo planteado por el análisis fisiológico del dolor, que lo contempla generalmente como una señal de alarma del organismo iniciado o causado por una lesión o disfunción del sistema nervioso, produciendo para ello ciertos reflejos de defensa o retirada al mismo tiempo que informa el lugar e intensidad de la agresión. Es por eso que hablamos inclusive acerca de la utilidad, así como de la necesidad del dolor; y que el interés de la exploración fisiológica se centre, entonces, en el conocimiento de los mecanismos del sistema nervioso en miras de la prevención y tratamiento del dolor a través de la introducción de factores que sean capaces de modificar, corregir o paralizar un organismo (Choza 1977, p. 41). Sin embargo, ¿esto es así realmente? Y es que, indudablemente nuestra cotidianeidad se halla repleta de ejemplos que nos permiten advertir que el dolor no posee primariamente, ni siempre, un papel defensivo (p. 42).

Scheler también se ha dado cuenta de ello y por tanto nos plantea tres puntos que echarían por tierra la consideración de que el sentido último del dolor y el sufrimiento radique en este fomento e inhibición de la vida, aunque nos parezca que esto sea 
así de hecho: En primer lugar nos dice que tal sistema de advertencia contenido en el dolor se encuentra regulado "sólo para los beneficios o daños específicamente típicos de cada organismo, y con los cuales este se encuentra por la misma naturaleza" (Scheler 2010, p. 53). Por ejemplo, la corteza cerebral se encuentra protegida por la coronilla del cráneo frente a intromisiones en casos normales y es por eso que le hace falta esa voz de alarma del dolor mediante la cual "cada órgano comunica al centro su amenaza [ya antes de que se realice el daño]" (p. 53). En segundo lugar, el fomento y la inhibición de la vida en donde el placer y el dolor actúan como pre-anuncios o reflejos interiores psíquicos, en realidad no refieren a toda la vida total del organismo, como individuo entero, sino que "la mayoría de las veces lo es sólo para la actividad vital de aquella parte del organismo y su estado momentáneo que ha sido primeramente afectada por el estímulo" (p. 54). Por último, y si rememoramos de nueva cuenta la naturaleza del dolor a través de cada uno de los estratos de profundidad de los sentimientos, notaremos que "aquel "fomento" e "inhibición" captado —o solo objetivamente anunciado - en la oposición placer-displacer dominante en todos los estratos no siempre se refiere [en el hombre], para los sentimientos de diferentes estratos, a lo mismo que se fomenta e inhibe" (p. 56). En otras palabras, la vida de todo el organismo se vive como amenazada, animada, retraída, impulsada etc. solo en los sentimientos vitales.

No, el sentido del dolor va más allá del avivamiento y el retraimiento de la vida que compartimos en lo esencial con los animales, puesto que también nos percatamos, a través de los estratos sentimentales más profundos del ser humano, "el perfeccionamiento y la autodegradación de nuestra persona espiritual anímica, cuya determinación moral y orientación fundamentalmente individual es independiente en sumo grado de nuestra vida animal" (p. 57). Ciertamente se ha dicho con anterioridad que el dolor queda reservado, principalmente, para el plano somático; las sensaciones sentimentales particulares e imprecisas —visto desde un ángulo scheleriano evidentemente- han de ser transformadas primero por el centro vital anímico en donde son «interrogadas»y «apreciadas»en su interacción, mediante funciones superiores sintéticas del sentir, con lo cual se descubre que el dolor no sólo informa el qué y el cómo (en relación al estado vital del todo orgánico), sino también (en atención a los sentimientos anímicos y espirituales) su porqué.

¿Por qué sufrimos? Indudablemente esta es una pregunta que compete enteramente a la persona ya que, como se observa, dicha interrogante no gira en torno a la descripción del mecanismo y caracterización del dolor; tampoco va tras el descubrimiento de su finalidad —en sentido utilitario—. No, la pregunta que el sujeto se está planteando tiene que ver con el plano más profundo de su ser. Es una pregunta por el sentido, y más aún, por el sentido último que compromete su existencia.

En vista de ello, Scheler llega a la conclusión de que la noción suprema y universal del sufrimiento (en donde se engloba desde la sensación dolorosa hasta la desesperación metafísico-religiosa) es la idea del sacrificio. En efecto, en su sentido más formal y metafísico todo sufrimiento "es la vivencia sacrificial de la parte por el todo y de lo inferiormente valioso [en sentido relativo], por lo superiormente valioso" (p. 58). Sólo 
así el dolor viene a adquirir una significación dentro de sí mismo, ya que —como se acaba de mostrar - la tesis fundamental aristotélica sobre el placer y displacer como signos del fomento e inhibición — ya sea de la vida, el alma o la persona espiritualno puede dar respuesta a las diversas preguntas que se forjan a raíz de la experiencia consciente y reflexiva del dolor (pp. 58-59).

Ahora bien, ¿cómo hemos de entender la idea de sacrificio? Antes que nada, Scheler reconoce que dicha comprensión última del sufrimiento depende de una experiencia religiosa y más aún, de una vivencia enmarcada dentro de la religión cristiana. Lo anterior parece justificarse si hiciésemos un fugaz avistamiento sobre el tratamiento del dolor dentro de la historia de las religiones, en donde advertimos que justamente es el cristianismo el que se distingue de las demás culturas arcaicas (y especialmente de la antigua moral mediterránea) por "haber trasformado el dolor, de un estado negativo, en la experiencia de contenido espiritual "positivo" (Eliade 1985, p. 89). De suerte que la presencia del dolor y el sufrimiento en el hombre (bajo esta perspectiva), lejos de observarse como una calamidad que ha de evitarse a toda costa, deberán comprenderse como instrumentos de purificación y de ascensión espiritual:

"Sólo situando la realidad del dolor y el sufrimiento — nos dice Scheler- a la luz de la idea del sacrificio como lo hiciera el cristianismo primero que nadie, por el pensamiento de que el mismo Dios ha sufrido libremente, por amor por nosotros, y de que se ha puesto en el lugar del hombre sacrificándose; sólo reconociendo el comportamiento cristiano, históricamente tan poderoso, llegaremos a una teodicea más profunda en el sufrimiento" (Scheler 2010, p. 60). No obstante, esto no parece ser una tarea sencilla. Scheler advierte que la noción de sacrificio es oscura y sumamente ambigua. En primer lugar, puede hablarse de sacrificio desde una vía objetiva, en donde la realización de un bien de rango superior destruya o disminuya, necesariamente, a un bien comparativamente de rango inferior. Mas, en tal caso, solo puede hablarse de "costos", pero no de "sacrificios". Pensemos por ejemplo en una persona que se somete a un régimen alimenticio para perder peso; ciertamente tendrá que sacrificarse y prescindir de los placeres generados por las golosinas y demás alimentos prohibidos, sin embargo, la idea de una figura mucho más esbelta (un bien, sin duda mucho más duradero), le motiva e impulsa a seguir:

Quien prefiere solo un placer mayor a uno menor, uno más duradero en el futuro a uno breve presente [de la misma clase], un mal y un sufrimiento menor a uno mayor, un placer mayor al mal menor ligado a su causa, no ofrece por ello ningún "sacrificio": únicamente calcula correctamente los "costos"(p. 60).

No, la idea del sufrimiento contiene algo más que el simple cálculo de bienes y males, placeres y tribulaciones; supone, en efecto, una supresión definitiva, una pérdida de bienes y placeres sin retribución y una aceptación definitiva de aquellos males y dolores. Aunque, así como en el sentido objetivo, así también en el subjetivo, todo sacrificio es necesariamente un sacrificio por algo (de ahí que, para Scheler, la idea del "dolor por el dolor" —el masoquismo — sea por demás absurda), es el 
sacrificio de la parte por el todo, de lo menos valioso por lo más valioso. Es por ello que el muniqués no duda en afirmar que, efectivamente, "todos los modos de dolor y sufrimiento son en sí sólo los reflejos y correlatos subjetivos, anímicos, de procesos sacrificiales [objetivos]; esto es, de tendencias eficaces en las que se entrega un bien de orden inferior en favor de un bien de orden superior" (p. 61).

Siguiendo esta visión, Scheler decide replantearse nuevamente el problema acerca de la naturaleza del dolor, mismo que vincularía de forma íntima con la idea de la muerte natural, sin duda uno de los pensamientos más dolorosos que el hombre pueda soportar; mas, si nos apegamos a la idea scheleriana del sacrificio, posee su sentido en ser el sacrificio natural del individuo con beneficio de la propagación y conservación de la especie. La relación del dolor parece evidente: éste representa una suerte de signo de la "muerte en pequeño"; un sacrificio de la parte por la conservación del todo orgánico: "lo que llamamos dolor —en palabras del muniqués — es sólo el 'tomar conciencia' de la necesaria limitación e inhibición respecto al todo que una unidad vital [parcial] (llámese célula, tejido, órgano, sistema orgánico) experimenta por estar incorporada como elemento que sirve a un todo organizado" (p. 64).

De igual modo, dolor y muerte se enlazan por el hecho de que su realidad se intensifica en la medida en que va complejizándose la organización del ser vivo. Por eso, si el dolor y la muerte se encuentran presentes en el hombre, no sólo desde un aspecto vital, sino también anímico y espiritual, parece claro el hecho de que también el amor se encuentra unido de un modo inminente a estos dos elementos. Ciertamente, la idea del amor posee — para nuestro autor - una importancia vital en el andamiaje de nuestra vida emocional. De suerte que tal sentimiento:

Como fuerza originaria de toda cohesión en el espacio y de toda propagación en el tiempo, crea con ello la primera condición de sacrificio. Muerte y dolor proceden del amor y no existirían sin él. Todo amor es un amor-sacrificio, eco en la conciencia del sacrificio en una parte por cuenta del todo que se transforma (Oyarzun 1981, p. 91).

Es así como podemos observar contenido en el sufrimiento una bifurcación. Por un lado, nos encontramos con el "dolor de la impotencia", de la pobreza y la imposibilidad de oponerse a un todo superior; por otro lado, tenemos al dolor que se origina en el fenómeno opuesto, esto es, una actividad supranormal de la parte frente al todo, "dolor de crecimiento", de la evolución (Scheler 2010, p. 66). Ambos son sin lugar a dudas sacrificio, el segundo más noble que el primero, sin embargo, no se puede querer lo uno sin el otro: "no es amor y la asociación (comunidad) sin la muerte y el dolor; no el perfeccionamiento y crecimiento de la vida sin el dolor y la muerte; no la dulzura del amor sin el sacrificio y su dolor" (p. 68). El dolor y la muerte son hechos irreductibles, ineludibles a los ojos del entendimiento, pero para el corazón su finalidad se ve ampliada. El dolor también ayuda al crecimiento integral de la persona, es su sentido pedagógico. 
He aquí entonces, la verdadera cara del dolor, la esencia del sufrimiento encarnada en la idea sacrificial: " $\mathrm{el}$ sacrificio es como una cabeza de Jano, cuyas caras a la vez sonríen y lloran!” (p. 68). El sufrimiento, el más profundo supone tanto la alegría como la pena de ceder una parte de vida por aquello que se ama: "en el sacrificio del amor espiritual libremente consentido, en el cual, en un mismo acto, el hombre experimenta la serenidad del amor y el dolor de perder el bien que por amor cede" (Oyarzun 1981, p. 91). Ahora parece tener mucho más sentido la connotación cristiana que el filósofo de Múnich ha dado al tema.

Por último, Scheler nos habla acerca de la idea de la purificación, la cual se desenvolvería como el sentido último de todo sufrimiento que sea revelado en el amor, el conocimiento y la acción: "purificación por medio del amor misericordioso de Dios, que envía el sufrimiento como un amigo del alma" (Scheler 2010, p. 108). Ahora bien, debe evitarse la idea de que el cristianismo promueva un valor positivo a todos los padecimientos por sí; que por el simple hecho de sufrir se crezca moral y religiosamente (ya dijimos que un dolor de cabeza ocasional e incluso continuo, una decepción profesional o sentimental, o bien hasta la muerte de un ser querido, si bien son experiencias afectivas de distinta profundidad, eso no quiere decir que sean una condición suficiente para el acaecimiento del sufrimiento espiritual), sino más bien que los dolores y sufrimientos de la vida: "dirigen en cierto modo nuestra mirada espiritual, cada vez más a los bienes centrales [espirituales] de la vida, y a los bienes de la salvación, a todos aquellos bienes [sobre todo] que, según la fe del cristiano, se nos ofrecen en la gracia y redención de Cristo" (p. 108). Sin duda, para el cristianismo el dolor siempre ha de entenderse como un mal, ya sea éste como un mal moral (es decir, el pecado, la injusticia) o un mal eudemonológico (la infelicidad, el sufrimiento), sin embargo, es a través del amor divino, fuente última de sentido de todo lo existente en que todas las tribulaciones van adquiriendo un significado, un carácter de gracia en términos schelerianos, en la medida que nos adentramos cada vez más en lo profundo de nosotros mismos: "la experiencia de la purificación consiste en penetrar — mediante el sufrimiento en los niveles más periféricos_ en los "castillos del alma" cada vez más profundos y en mantenerse aquí cada vez más abierto a la recepción de un mundo superior de fuerzas espirituales" (p. 113). En suma, al reconocer la importancia del amor y el sacrificio (y su inclusión en la religión cristiana), parece que Scheler nos ha proporcionado bastante luminosidad hacia el problema del dolor.

\section{Dolor, sufrimiento y crisis del hombre}

¿Cuál es la visión de nuestro mundo actual? En nuestra opinión, diríamos que la de un claroscuro. En efecto, se dice que este es el mundo del progreso, de la ciencia, la técnica y la política, pero también este es un mundo en donde el problema de la crisis se antoja mucho más abrumante que en otras épocas, no sólo en las esferas más altas del saber y el hacer humano, sino también dentro de los confines de su propia intimidad. No pocos pensadores han coincidido (especialmente dentro del terreno personalista, la ética y el humanismo de corte cristiano) que la vida actual se halla inmersa en una 
terrible angustia generada en gran medida por la distorsión del raciocinio, la desmoralización radical de la humanidad y la ausencia de Dios. El hombre, ha perdido la conciencia de su propia humanidad debido a que ya no vive dentro de sí, sino al revés, es decir, vive fuera de sí, absorbido por el entorno, los medios de comunicación masiva y por una vida inauténtica que lo hace pensar tan sólo en los fines próximos, sin relacionarlos con su fin último.

Es factible pensar entonces, que el ser humano haya dejado también de sentir. No lo decimos estrictamente desde un terreno físico (aunque sí puede darse el caso de una suerte de desatención masiva de los afectos, acentuado por esta vivencia extática que padece la humanidad contemporánea), sino más bien desde una acepción anímica e incluso espiritual. O bien, que el hombre quizás sienta demasiado, es decir, que haya puesto en duda y relativizado sus facultades superiores y más profundas (inteligencia, voluntad, corazón), para así entregarse por completo hacia las vivencias más inmediatas o sea, las sensibles, vitales y anímicas; vivencias sentimentales que no son contempladas en su plenitud, dando pie con ello a un estado sentimentalista en donde el hombre, simplemente se adhiere a lo que le gusta y evita lo que no le disgusta; una moral hedonista que lleva consigo una vida superficial que deja de buscar objetivos altos y profundos por aquellos más bajos e inmediatos. Esta es pues, nuestra típica sociedad de consumo que se contenta con la realización de los sentimientos más sensitivos. En lo tocante a nuestro tema central, lo anterior mencionado se reafirma. Fuera del carácter previsor que poseen ambas vivencias afectivas, el sufrimiento, visto desde un punto de vista general, lo entenderemos como aquello que el hombre quiere evadir a toda costa ya que, vinculado a la idea del dolor y la aflicción, se halla de forma contraria a la idea de bienestar; es la señal de que algo anda mal, de que algo falta. El ser humano, en todas sus épocas y por lo general, procura evitar muchos problemas fundamentales debido a la falta de experiencia personal, aunado al temor de encontrarse con su propia finitud, con su fragilidad e inestabilidad, socavando de esta manera su personalidad. El hombre busca a toda costa minimizar e incluso suprimir todo dolor, toda situación desagradable o penante; de ahí que observamos la idea del progreso encaminada a mejorar tanto la calidad como el estilo de vida de los individuos. Sin embargo, la anulación de cualquier tipo de dolor no es más que el reflejo del pavor que manifiesta el hombre de, la cual sale a relucir a través de aquellas situaciones límite que "aprietan al hombre por delante y por detrás, poniéndole la conciencia en vilo, evidenciando la soledad y el vacío inquietante de la existencia” (Jiménez 1999, p. 183). Y es que, los desastres naturales, terremotos, sequias, inundaciones, temperaturas extremas, hambruna, enfermedades, guerras políticas o religiosas, terrorismo y otras situaciones de dolor, daño o injusticia que usualmente debilitan o doblegan a los hombres, le permiten también descubrirse a sí mismos como un ser endeble y vulnerable, pese a la esplendidez con la que se conduce por el mundo a lo largo de su historia. El hombre de hoy — quizás el de siempre — se ve sumido desde lo más profundo de su ser en una constante contradicción: por un lado, es esplendor y grandeza; por otro lado, ocaso y miseria. 
En esta larga marcha hacia el hombre que se concreta en ser un itinerario hacia sí mismo en cada uno de los hombres, le salen al paso dos caras de lo humano, la de la pequeñez y la de la grandeza, la miseria y el esplendor, la de la vileza y la de la dignidad. Son las dos dimensiones de lo humano, la cara y la cruz del hombre (Forment 1998, p. 358).

No obstante, es precisamente en estas situaciones, cuando mayor es el malestar mostrado en las sociedades y en los corazones de los hombres en un determinado periodo histórico, más apremiante se torna la necesidad por comprenderse a sí mismo y responder a la pregunta en torno a la naturaleza y significado del dolor físico y el sufrimiento en general. Como hemos podido observar, examinar el fenómeno de la afectividad y, sobre todo, ir hacia las entrañas del sufrimiento no ha sido cosa fácil ya que, por una parte, hemos tenido que lidiar con una serie de prejuicios que han caracterizado al terreno sentimental, situándolo como algo ambiguo y oscuro; una emoción de índole personal cuya enmarcación se dificulta debido a su forma tan peculiar de manifestarse en cada hombre. Por otra parte, el tema del dolor y el sufrimiento se ha visto envuelto desde siempre en una estigmatización pues dichas vivencias son contempladas ya sea como el producto de una falta personal, la acción efectuada por la maldad de un enemigo o el resultado de la voluntad o el enojo del Ser supremo. El sufrimiento entonces adquiere además un carácter religioso y místico al ser considerado como el recuerdo permanente del alejamiento del hombre con Dios, la marca imborrable que los diferencia.

A propósito de lo anterior, son varias las preguntas que suelen hacerse con respecto al fenómeno del sufrimiento vinculado a la idea de Dios. Sin duda, una de las principales es aquella que cuestiona la pertinencia y ecuanimidad del dolor: si Dios es tan bueno, entonces ¿por qué permite el sufrimiento? Esta pregunta ha sido formulada de manera reiterativa por hombres religiosos y ateos por igual. Ambos parecen tener respuestas consistentes ante tal interrogante, mismas que inclusive han llegado a confrontarse vehementemente, más la realidad es que al analizarlas con un mayor detenimiento, advertimos que ninguna de ellas puede ser del todo rotunda.

¿Por qué Dios permite el sufrimiento? Si la Tierra en su totalidad fue creada por su gracia mientras que el hombre fue diseñado amorosamente a su semejanza, entonces ¿Por qué admite el dolor y la pena en ellos? Si son ciertos todos aquellos registros legados por la Biblia en donde nos muestra la existencia y más aún, su recia presencia que constantemente se mostraba igualmente en individuos que, en multitudes enteras, ¿por qué ahora, en estos momentos donde se necesita más que nunca, pareciera ser más notoria su ausencia? ¿Qué clase de Dios, por ejemplo, deja morir a cientos de miles de personas inocentes a causa de hechos violentos y guerras en todo el mundo? Lo cual genera otra pregunta aún más interesante: ¿cuáles son las verdaderas intenciones de Dios? Es decir, si es que existe un Dios, ¿es realmente de una naturaleza bondadosa aunque violenta que siempre quiere lo mejor para nosotros, sus hijos, los hombres o acaso es el caso de que estamos ante una deidad aciaga, que admite e incluso disfrute 
que los hombres sufran y se hagan daño entre sí?, ¿será simplemente que, desde hace mucho tiempo dios nos ha abandonado a nuestra suerte y es por ello que no tenemos respuesta alguna cada vez que se alza la mirada ante una cruz con la esperanza de mitigar, aunque sea un poco, nuestros males?, ¿Será que es cierto el hecho que Dios murió y ni siquiera estamos enterados?

Ante todas estas preguntas, lo que sobran son las respuestas, unas más alentadoras que otras, sin embargo, la realidad es que tanto el dolor como el sufrimiento humano se constituyen como cuestiones últimas de las cuales no existe hasta el momento una respuesta definitiva. Lo anterior ha desencadenado el hecho de que ambas vivencias se consideren muchas veces como hechos absurdos y crueles, sin que tengamos siquiera la posibilidad de reclamo o consuelo alguno, menos una justificación racional. Si recordamos las palabras de García-Baró, el dolor verdadero se presenta cuando el hombre experimenta la presencia autentica del mal. Ahora bien, "el mal pésimo y más hondo o pesante es el sinsentido; un contrasentido de tal furia destructiva que arruina el sentido y que, por tanto, desespera" (García-Baró 2006, p. 240). Es así como el sufrimiento posee una fama punitiva y desagradable, cerrando la posibilidad de poder encontrarle un sentido positivo. Nuestra propuesta versa precisamente en el sentido contrario, es decir, abrir la posibilidad de hallar un sentido positivo en el sufrimiento, sin dejar de considerarlo a su vez como un sentimiento negativo.

A través de la tesis scheleriana sobre el sentido del dolor a través de la idea del sufrimiento, se ha podido considerar la utilidad y conveniencia de estas vivencias, debido a que desencadenan el percato de ciertas intuiciones y hasta certezas que, en algún otro estado anímico, no sería posible descubrirlas. El sufrimiento posee un nexo con la idea de purificación y revelación. Efectivamente, en la medida en que el hombre experimenta el dolor (ya sea físico o emocional), participa con él padeciéndolo, lo cual provoca que se ponga en contacto con sus propios límites, dado que el dolor perturba su estado natural recordándole su infinitud, su fragilidad. De este hecho surge la necesidad de esclarecer su causa — esto con el fin de volverlo soportable-, entendiéndolo entonces como la pérdida de un bien, la cólera de un dios o la acción (ya sea física o esotérica) de algún enemigo. Sea cual sea el caso, dichas explicaciones permiten en el hombre la aceptación de su sufrimiento, lo cual no significa en forma alguna la supresión de este sino más bien, que aprende a convivir con él.

Es así como el sufrimiento, conlleva a una purificación del alma y a un estado de sabiduría de índole espiritual. Si bien no hay que olvidar que los dolores y penas extremas pueden llegar a trastornar y destruir la estabilidad del sujeto, también es cierto de que dichas experiencias lo lanzan hacia una especie de despertar a la conciencia, es decir, una conciencia de sí mismo en tanto que conocimiento del ser personal, dado que es capaz de situarlo a su vez frente a lo inmediato y lo real. El sufrimiento, indudablemente, marca una línea divisoria en el hombre entre el antes y el después. Nadie permanece igual después de haber sufrido gravemente. Sin embargo, cuando se siente la fatiga que provoca el cáncer de la pena, cuando se han experimentado los sufrimientos más terribles, las muertes más atroces las penas más terribles, allí donde se siente la agonía y el asco resultante de saberse finito y absurdo en el mundo, cobran 
un sentido especial en la oscuridad de la noche, en la más profunda soledad que nos aleja del cielo y la tierra desatándonos ante el drama de nuestra finitud, es cuando tenemos la oportunidad de sobreponernos al sentimentalismo y la desesperación propia de estas vivencias para dar paso así a la reflexión y el amor.

\section{Referencias}

Aristóteles 2011, Acerca del alma, Gredos, Madrid.

Beites, P., 2010, “Libertad y 'ordo amoris': una alternativa al existencialismo", en I. García de Leániz, Ignacio (Ed.), De nobis Ipsis Silemus. Homenaje a Juan Miguel Palacios, Encuentro, Madrid.

Eliade, M., 1985, El mito del eterno retorno, Planeta, Barcelona.

Estermann, J., 2001, Historia de la filosofía II, Vol. III, Abya Yala, Ecuador.

Forment, E, 1998, Historia de la filosofía tomista en la España contemporánea, Encuentro, Madrid.

García-Baró, M., 2006, Del dolor, la verdad y el bien, Sígueme, Salamanca.

García, J. M., \& López, M., 2009, "El dolor. Una encrucijada entre cuerpo y subjetividad" $1^{\circ}$ parte, Alcmeon, Revista Argentina de Clínica Neuropsiquiátrica, 16(1), pp. $25-40$.

Heidegger, M., 2009, Principios metafisicos de la lógica, Síntesis, Madrid.

Husserl, E., 1962, Ideas relativas a una fenomenología pura y una filosofía fenomenológica, Fondo de Cultura Económica, México.

Jiménez, E., 1999, ¿Quién soy yo?, Caparrós, Madrid.

Kogan, J., 1996, Temas de filosofía, La belleza, el bien, el hombre, la realidad, Biblos, Buenos Aires.

H. Merskey, H. \& Bogduk, N., 1994, "Part III: Pain Terms, A Current List with Definitions and Notes on Usage", en Classification of Chronic Pain, IASP Task Force on Taxonomy, IASP Press, Seattle, pp. 209-214.

Michael, K., 2003, Diccionario Oxford de medicina y ciencias del deporte, Paidotribo, Barcelona.

Morris, D., 2014, La cultura del dolor, Andrés Bello, Santiago de Chile.

Oyarzun, L., 1981, "Max Scheler y la idea de sacrificio", en J. O. Cofré, Ed., Meditaciones estéticas, pp. 87-120, Editorial Universitaria, Santiago de Chile.

Polo, L., 2015, La persona humana y su crecimiento/ La originalidad de la concepción cristiana de la existencia en Obras Completas, vol., XIII, EUNSA, Pamplona.

Real Academia Española RAE, 2019, “Dolor”, Edición Tricentenario, Rae.es., recuperado de link: http://lema.rae.es/dpd/srv/search?key=dolor

Scheler, M., 2010, “El sentido del sufrimiento", en Amor y conocimiento y otros escritos, Palabra, Madrid.

Vicente Arregui, J., \& Choza, J., 1992, Filosofía del hombre, una Antropología de la intimidad, Rialp, Madrid. 